\title{
Global imprint of climate change on marine life
}

\author{
Elvira S. Poloczanska ${ }^{1 \star}$, Christopher J. Brown ${ }^{1,2 \dagger}$, William J. Sydeman ${ }^{3}$, Wolfgang Kiessling ${ }^{4,5}$, \\ David S. Schoeman ${ }^{6,7}$, Pippa J. Moore ${ }^{8,9}$, Keith Brander ${ }^{10}$, John F. Bruno ${ }^{11}$, Lauren B. Buckley ${ }^{11}$, \\ Michael T. Burrows ${ }^{12}$, Carlos M. Duarte ${ }^{13,14}$, Benjamin S. Halpern ${ }^{15}$, Johnna Holding ${ }^{13}$, \\ Carrie V. Kappel ${ }^{15}$, Mary I. O'Connor ${ }^{16}$, John M. Pandolfi ${ }^{17}$, Camille Parmesan ${ }^{18,19}$, Franklin Schwing ${ }^{20}$, \\ Sarah Ann Thompson ${ }^{3}$ and Anthony J. Richardson ${ }^{1,21}$
}

Past meta-analyses of the response of marine organisms to climate change have examined a limited range of locations ${ }^{1,2}$, taxonomic groups ${ }^{2-4}$ and/or biological responses ${ }^{5,6}$. This has precluded a robust overview of the effect of climate change in the global ocean. Here, we synthesized all available studies of the consistency of marine ecological observations with expectations under climate change. This yielded a metadatabase of 1,735 marine biological responses for which either regional or global climate change was considered as a driver. Included were instances of marine taxa responding as expected, in a manner inconsistent with expectations, and taxa demonstrating no response. From this database, 81-83\% of all observations for distribution, phenology, community composition, abundance, demography and calcification across taxa and ocean basins were consistent with the expected impacts of climate change. Of the species responding to climate change, rates of distribution shifts were, on average, consistent with those required to track ocean surface temperature changes. Conversely, we did not find a relationship between regional shifts in spring phenology and the seasonality of temperature. Rates of observed shifts in species' distributions and phenology are comparable to, or greater, than those for terrestrial systems.

Despite the ocean having absorbed $>80 \%$ of the heat added to the global climate system, the ocean's thermal capacity has led to surface waters warming three times slower than air temperatures over land ${ }^{7}$. Nevertheless, isotherms at the ocean surface have migrated at comparable or faster rates than isotherms over land during the past 50 years $(1960-2009)^{8}$. Winter and spring temperatures, over both the ocean and land, are warming fastest, which might advance phenological events such as the start of growing seasons and the timing of reproduction ${ }^{7}$. In addition, anthropogenic $\mathrm{CO}_{2}$ uptake by the oceans is altering seawater carbonate chemistry, which can reduce calcification rates and impact physiological processes in some marine organisms ${ }^{9,10}$. Given these findings, we expect marine organisms to have responded to recent climate change, with magnitudes similar to or greater than those found for terrestrial species.

We investigated the peer-reviewed literature that addresses the question of whether or not climate change impacts marine ecological phenomena, and found 208 studies of 857 species and assemblages. From these, we extracted 1,735 observations (median time span $=41 \mathrm{yr}$, range $=19-343 \mathrm{yr}$, Supplementary Fig. S1, plus two subfossil comparisons spanning $>12,000 \mathrm{yr}$ ) of the following types of response: distribution, phenology, abundance, community change, calcification and demography. We included responses irrespective of whether they were consistent with expectations under climate change or not, as well as null responses (Fig. 1). Data were available for every ocean (Fig. 1a), although most reports were from Northern Hemisphere temperate oceans (Fig. 1b).

We analysed this meta-database to estimate mean shifts in distribution and phenology among marine taxonomic or functional groups (data subset given in Table 1). We assessed relationships between the magnitude of observed changes in distribution and spring phenology with regional temperature shifts, and evaluated whether there is a global imprint of climate change on changes in marine life, by comparing consistent and inconsistent observations

\footnotetext{
${ }^{1}$ Climate Adaptation Flagship, CSIRO Marine and Atmospheric Research, Ecosciences Precinct, GPO Box 2583, Brisbane, Queensland 4102, Australia, ${ }^{2}$ School of Biological Sciences, The University of Queensland, St Lucia, Queensland 4072, Australia, ${ }^{3}$ Farallon Institute for Advanced Ecosystem Research, $101 \mathrm{H}$ Street, Suite Q, Petaluma, California 94952, USA, ${ }^{4}$ Museum für Naturkunde, Leibniz Institute for Research on Evolution and Biodiversity, Invalidenstrasse 43, 10115 Berlin, Germany, ${ }^{5}$ GeoZentrum Nordbayern, Paläoumwelt, Universität Erlangen-Nürnberg, Loewenichstr. 28, 91054 Erlangen, Germany, ${ }^{6}$ Faculty of Science, Health and Education, University of the Sunshine Coast, Maroochydore, Queensland 4558, Australia, ${ }^{7}$ Department of Zoology, Nelson Mandela Metropolitan University, Port Elizabeth, South Africa, ${ }^{8}$ Centre for Marine Ecosystems Research, Edith Cowan University, Perth, Western Australia 6027, Australia, ${ }^{9}$ Institute of Biological, Environmental and Rural Sciences, Aberystwyth University, Aberystwyth SY23 3DA, UK, ${ }^{10}$ DTU Aqua-Centre for Ocean Life, Technical University of Denmark, Charlottenlund Slot, DK-2920 Charlottenlund, Denmark, ${ }^{11}$ Department of Biology, The University of North Carolina at Chapel Hill, Chapel Hill, North Carolina 27599, USA, ${ }^{2}$ Scottish Association for Marine Science, Scottish Marine Institute, Oban, PA37 1QA, UK, ${ }^{13}$ Department of Global Change Research, IMEDEA (UIB-CSIC), Instituto Mediterráneo de Estudios Avanzados, 07190 Esporles, Mallorca, Spain, ${ }^{14}$ The UWA Oceans Institute, University of Western Australia, 35 Stirling Highway, Crawley 6009, Western Australia, Australia, ${ }^{15}$ National Center for Ecological Analysis and Synthesis, 735 State Street, Suite 300, Santa Barbara, California 93101, USA, ${ }^{16}$ University of British Columbia, Department of Zoology, Vancouver, British Columbia V6T 1Z4, Canada, ${ }^{17}$ Australian Research Council Centre of Excellence for Coral Reef Studies, School of Biological Sciences, The University of Queensland, St Lucia, Queensland 4072, Australia, ${ }^{18}$ Integrative Biology, Patterson Laboratories 141 , University of Texas, Austin, Texas 78712, USA, ${ }^{19}$ Marine Institute, A425 Portland Square, Drake Circus, University of Plymouth, Plymouth PL4 8AA, UK, 20 Office of Sustainable Fisheries, NOAA Fisheries Service, 1315 East-West Hwy, Silver Spring, Maryland 20910-3282, USA, ${ }^{21}$ Centre for Applications in Natural Resource Mathematics (CARM), School of Mathematics and Physics, University of Queensland, St Lucia, Queensland 4072, Australia. 'Present address: Global Change Institute, The University of Queensland, St Lucia, Queensland 4072, Australia. *e-mail: elvira.poloczanska@csiro.au
} 
a

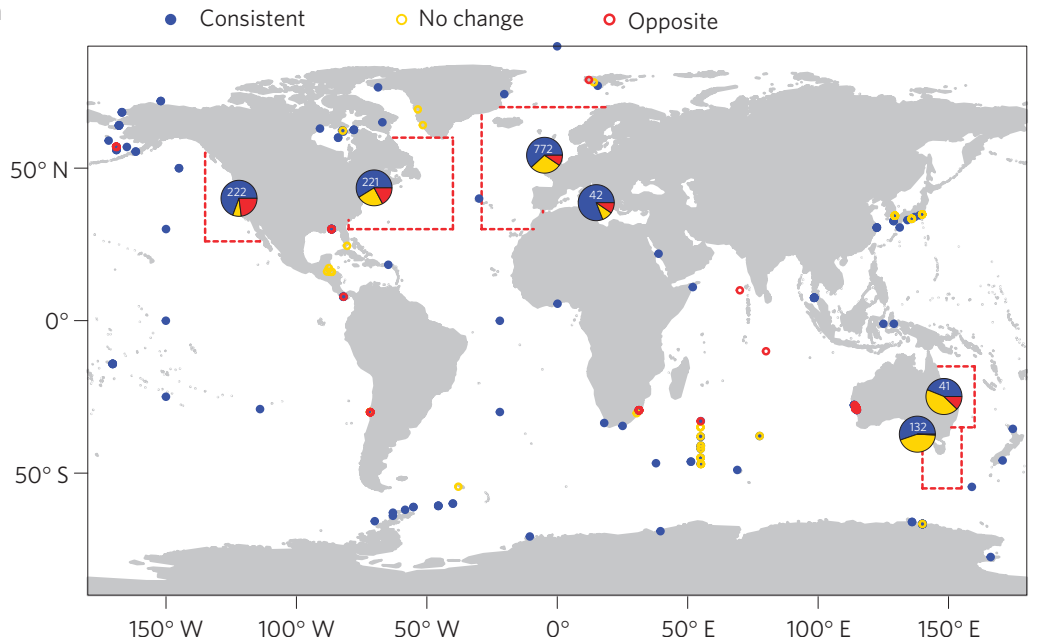

b

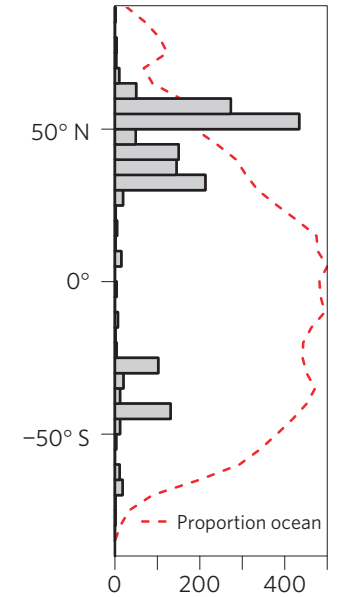

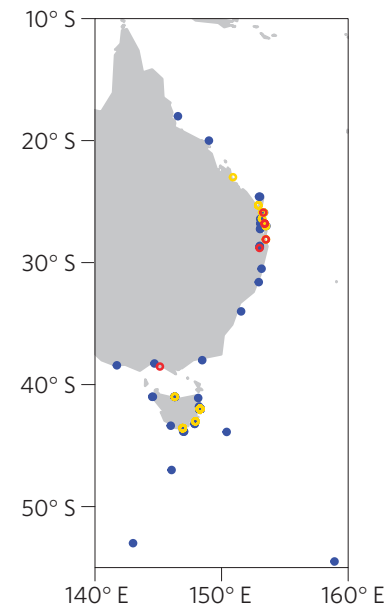

e

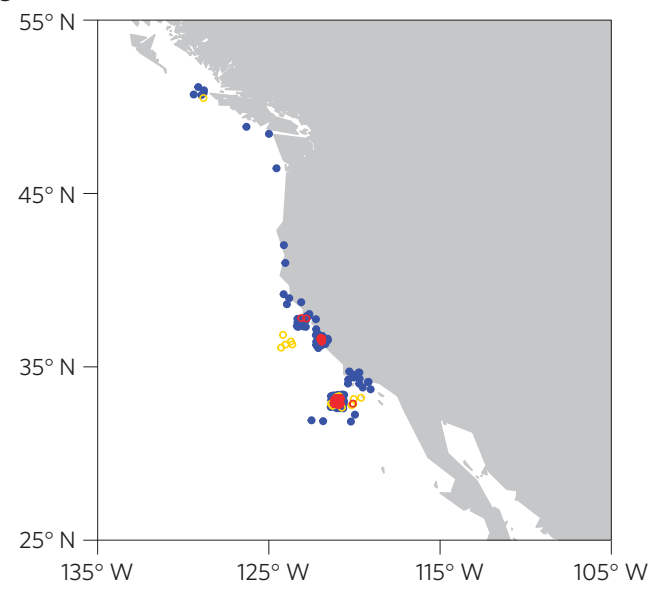

d

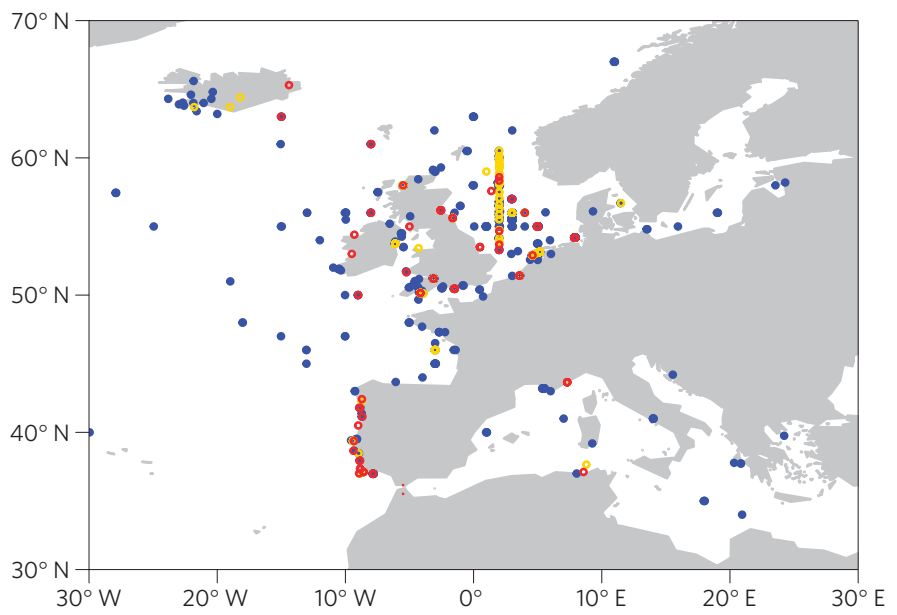

f

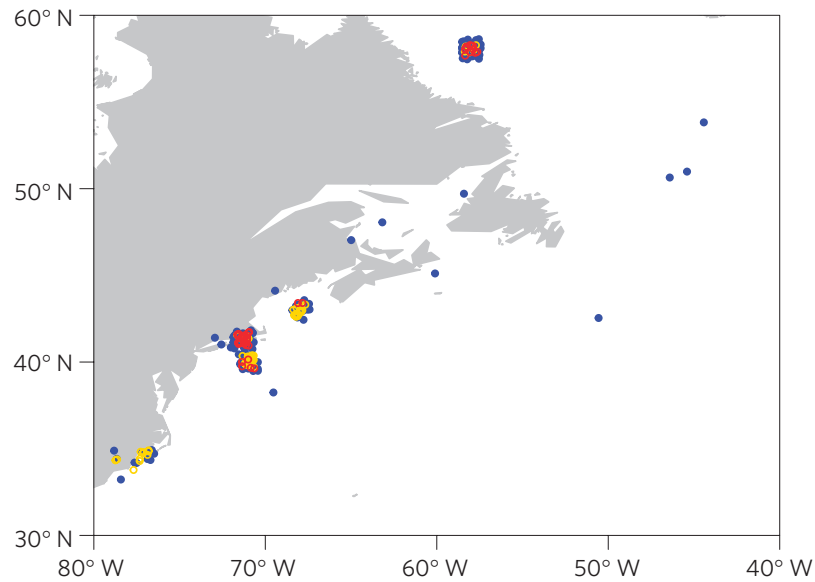

Figure 1| a, Observed responses $(n=1,735)$ of marine organisms to climate change from 208 single- and multi-species studies showing responses that are consistent with climate change (blue, $n=1,092$ ), opposite to expected (red, $n=225$ ) or are equivocal (yellow, $n=418$ ). Each circle represents the centre of a study area. Where points fall on land, it is because they are centroids of distribution that surround an island or peninsula. Pie charts show the proportions within regions bounded by red squares and in the Mediterranean Sea; numbers indicate the total (consistent, opposite plus equivocal) observations within each region. $\mathbf{b}$, Frequency of observations and ocean area by $5^{\circ}$ latitudinal bins; red dotted line shows the proportion of ocean area within each latitudinal bin. c, Observations from the California Current. d, Northeast Atlantic, North Sea and Mediterranean Sea. e, Southwest Pacific. f, Northwest Atlantic.

across all types of response. The inclusion of single-species studies in meta-analyses of climate change impacts might result in positive publication bias due to possible under-reporting of non-responses ${ }^{11,12}$. However, our meta-database contains only 181 observations $(<11 \%)$ from single-species studies and many of these are from fisheries-driven studies that were designed to detect 
Table 1 | Rates of change in phenology and distribution from this study (marine) compared to results from previous studies in both marine and terrestrial systems.

\begin{tabular}{|c|c|c|c|c|c|c|}
\hline Study & Observation & Shift (mean \pm s.e.m.) & $n$ studies & $n$ observations & $\begin{array}{l}\text { Realm (\% } \\
\text { studies) }\end{array}$ & $\begin{array}{l}\text { Data } \\
\text { criteria }\end{array}$ \\
\hline & \multicolumn{6}{|l|}{ Phenology } \\
\hline This study & Summer & $-4.4 \pm 0.7$ days $\mathrm{dec}^{-1}$ & 10 & 51 & Marine $100 \%$ & $\begin{array}{l}\text { Single }^{\dagger} \text { and multi-species } \\
\text { studies, climate change inferred }\end{array}$ \\
\hline This study & Spring & $-4.4 \pm 1.1$ days $\operatorname{dec}^{-1}$ & 17 & 52 & Marine $100 \%$ & $\begin{array}{l}\text { Single }{ }^{\dagger} \text { and multi-species } \\
\text { studies, climate change inferred }\end{array}$ \\
\hline Ref. 20 & Spring & -1.1 to -3.3 days $\mathrm{dec}^{-1}$ & $\mathrm{n} / \mathrm{a}$ & 1,634 & Terrestrial 100\% & $\begin{array}{l}\text { Long-term observations of plant } \\
\text { phenology from NECTAR } \\
\text { database }\end{array}$ \\
\hline Ref. 12 (ref. 11) & Spring & $-2.8 \pm 0.35$ days $\mathrm{dec}^{-1}$ & 9 & 203 & $\begin{array}{l}\text { Terrestrial } 91 \%, \\
\text { Fresh water } 8 \% \text {, } \\
\text { Marine } 1 \%\end{array}$ & $\begin{array}{l}\text { Multi-species studies, climate } \\
\text { change inferred }\end{array}$ \\
\hline \multirow[t]{4}{*}{ Ref. 3} & Spring & $-5.1 \pm 0.1$ days $\mathrm{dec}^{-1 \S}$ & 61 & 169 & Terrestrial 86\% & Minimum 10 yr time span from \\
\hline & & & & & Fresh water $10 \%$ & 1951 to 2001; observed shift \\
\hline & & & & & Marine 4\% & $\begin{array}{l}>1 \text { day dec }{ }^{-1} \text { or }>1 \text { day }{ }^{\circ} \mathrm{C}^{-1} \\
\text { single and multi-species studies }\end{array}$ \\
\hline & \multicolumn{6}{|l|}{ Distribution } \\
\hline This study & $\begin{array}{l}\text { Leading and trailing } \\
\text { edges plus centre }\end{array}$ & $30.6 \pm 5.2 \mathrm{~km} \mathrm{dec}^{-1}$ & 36 & 360 & Marine $100 \%$ & $\begin{array}{l}\text { Single }{ }^{\star} \text { and multi-species } \\
\text { studies, climate change inferred }\end{array}$ \\
\hline This study & Trailing edge & $15.4 \pm 8.7 \mathrm{~km} \mathrm{dec}^{-1}$ & 11 & 106 & Marine $100 \%$ & $\begin{array}{l}\text { Single }^{\star} \text { and multi-species } \\
\text { studies, climate change inferred }\end{array}$ \\
\hline This study & Leading edge & $72.0 \pm 13.5 \mathrm{~km} \mathrm{dec}^{-1}$ & 27 & 111 & Marine $100 \%$ & $\begin{array}{l}\text { Single }^{\dagger} \text { and multi-species } \\
\text { studies, climate change inferred }\end{array}$ \\
\hline Ref. 11 & Leading edge & $6.1 \pm 2.4 \mathrm{~km} \mathrm{dec}^{-1}$ & 4 & 99 & Terrestrial $100 \%$ & $\begin{array}{l}\text { Multi-species studies, climate } \\
\text { change inferred }\end{array}$ \\
\hline Ref. 2 & Leading edge & $19.7 \pm 3.7 \mathrm{~km} \mathrm{dec}^{-1 \|}$ & 3 & $\begin{array}{l}16 \text { groups } \\
\text { (336 species) }\end{array}$ & $\begin{array}{l}\text { Terrestrial } 83 \% \text {, } \\
\text { Fresh water } 15 \% \\
\text { Marine 3\% }\end{array}$ & $\begin{array}{l}\text { Multiple species studies }(\geq 4) \\
\text { that infer climate change, } \\
\text { average response of taxonomic } \\
\text { or functional group in a region }\end{array}$ \\
\hline Ref. 4 & Leading edge & $13.8 \pm 4.8 \mathrm{~km} \mathrm{dec}^{-1}$ & 11 & 85 & Marine $100 \%$ & Multi-species studies \\
\hline
\end{tabular}

The number of studies and number of observations (taxonomic or functional groups) from studies are given, together with a breakdown of studies by realm and biome. The criteria for data inclusion are outlined for each study. Seabirds, anadromous fish and polar bears were counted as marine, given their dependence on marine food sources, and wading birds were considered as freshwater birds. Minimum time span of observations within studies is 19 or 20 years, unless stated otherwise. ${ }^{*}<4 \%$ of total number of observations from single-species studies. ${ }^{\dagger}<10 \%$ of total number of observations from single-species studies. The network of ecological and climatological timings across regions. ${ }^{\varsigma}$ Correcting for methodological differences compared with ref. 11 gives a revised estimate of 3.1 days dec $^{-1}$ (ref. 12) that was not significantly different from the estimate reported in ref. 11. $\|$ Recalculated using leading-edge (cold limit) observations spanning $\geq 19 \mathrm{yr}$, and with data after 1990.

changes other than climate change and are therefore likely to have been published irrespective of whether they detect climate change impacts or not. Although this suggests that our database is relatively robust to publication bias, we nevertheless give all results both with and without single-species studies.

Characteristics common among marine organisms, such as high rates of propagule production and dispersal by ocean currents, might lead to faster expansions in distribution than observed for plants and animals on land, even at latitudes where velocities of isotherm migration over the ocean and land surfaces (19602009) have been comparable ${ }^{8}$ (Supplementary Table S4). Evidence of faster spread rates for marine than terrestrial organisms was previously shown for expansions of both native and introduced species $^{6}$. Here, focusing on responses to climate change, the mean rate $( \pm$ s.e.m. $)$ of expansion at the leading range edges for marine species was $72.0 \pm 13.5 \mathrm{~km} \mathrm{dec}^{-1}$ (Fig. $2 \mathrm{a}, 54.6 \pm 11.7 \mathrm{~km} \mathrm{dec}^{-1}$ excluding single-species studies) about an order of magnitude faster than rates reported for predominately terrestrial species $(6.1 \pm$ $2.4 \mathrm{~km} \mathrm{dec}^{-1}$; Table 1). We find the fastest leading-edge expansions in highly mobile or dispersive pelagic organisms: phytoplankton $\left(469.9 \pm 115.3 \mathrm{~km} \mathrm{dec}^{-1}\right)$, bony fish $\left(277.5 \pm 76.9 \mathrm{~km} \mathrm{dec}^{-1}\right)$ and invertebrate zooplankton $\left(142.1 \pm 27.8 \mathrm{~km} \mathrm{dec}^{-1}\right)$. We find the magnitude of distribution change differed by taxonomic or functional group $(p<0.0001, F=11.51, d f=8)$ and range edge $(p<0.0001, F=16.01, d f=1$; two-way analysis of variance with $d f$ residuals $=206$; no significant interaction between taxa and range edge). In the latter case, trailing-edge range contractions $\left(15.4 \pm 8.7 \mathrm{~km} \mathrm{dec}^{-1}\right)$ were significantly slower than leading-edge expansions $\left(72.0 \pm 13.5 \mathrm{~km} \mathrm{dec}^{-1}\right)$.

Recent analysis suggests that both leading and trailing range edges for ectothermic marine organisms are equally responsive to warming $^{13}$. Thus, our faster leading-edge shifts might be driven by stronger regional warming there compared with trailing-edge locations. Thirty-eight per cent of our leading-edge observations were from latitudes warming strongly ${ }^{8}\left(>40^{\circ} \mathrm{N}\right)$, whereas only $15 \%$ of trailing-edge observations were from temperate and polar regions. Hence, differences in expansion at leading and trailing edges may be explained by differences in regional climate change at the polar and equatorial edges of biogeographic distributions. A link between global warming patterns and the magnitude or frequency of multiple biological responses has been shown previously for predominately land species $^{2-4}$, but not for marine species $^{5}$. However, new indices, such as the velocity of temperature change ${ }^{8,14}$ and seasonal shift in temperature ${ }^{8}$, describe the pace and direction of climate change and thus provide improved expectations for biological shifts ${ }^{15}$. 
a
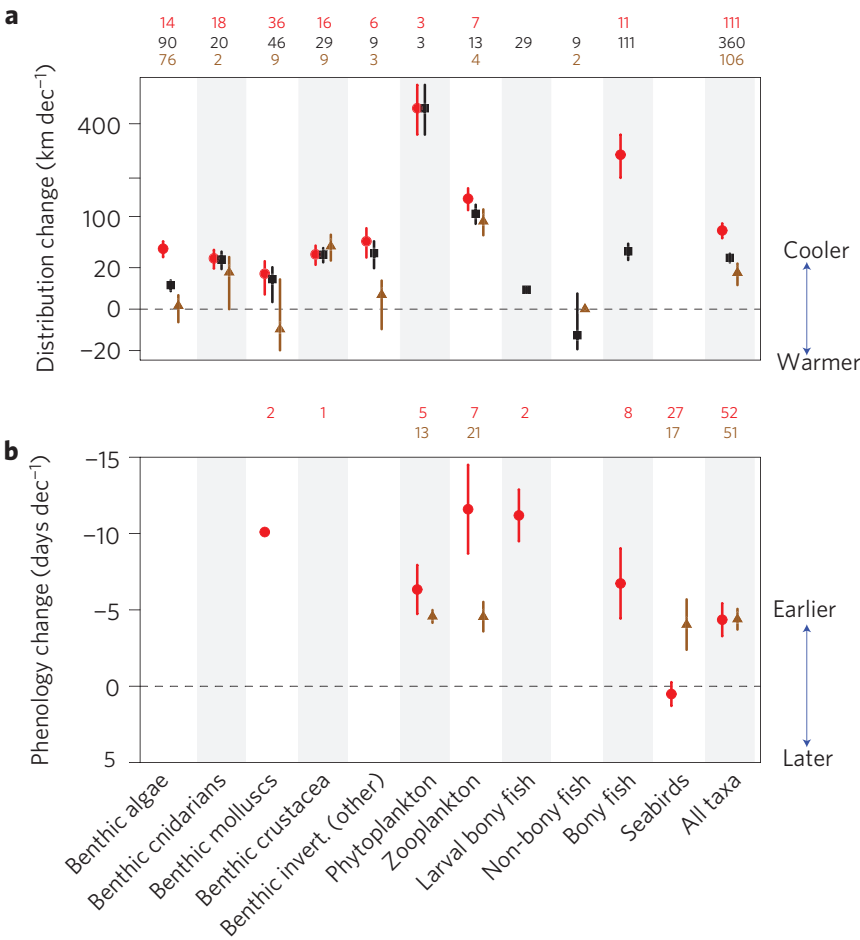

Figure $2 \mid \mathbf{a}, \mathbf{b}$, Rates of change (means \pm s.e.m.) of marine taxonomic or functional groups in distribution $\left(\mathrm{km} \mathrm{dec}^{-1}\right)$ at the leading edges (red circles), trailing edges (brown triangles) and from all data regardless of range location (black squares) (a), and phenology (days $\mathrm{dec}^{-1}$ ) during spring (red circles) and summer (brown triangles) (b). Axis scaled on square-root for display, so standard errors are asymmetric. Negative phenological changes (generally earlier) and positive distribution changes (generally poleward into previously cooler waters) are consistent with warming. Sample sizes $(n)$ are given above each taxon or functional group (a, leading edges upper row, trailing edge lower row; $\mathbf{b}$, spring upper row).

For each quantified shift in distribution in our database, we generated corresponding quantitative expectations based on the decadal rate of temperature velocity for the period $1960-2009^{8}$ (see Supplementary Methods). Taking the distance shifted by species that show a response $(n=279$; those that did not show a response were not included because failure to detect a change in distribution may have several causes, including barriers to dispersal, poor sampling resolution or the dominance of alternative drivers of change $\left.{ }^{11}\right)$, and weighting by the numbers of years during which observations were made, yields a significant relationship with rates of isotherm shift (regression using fourth-root transformed data of observed shifts against shifts expected from velocity multiplied by time span: $y=1.460+0.514 \cdot x, R^{2}=0.11, P<0.0001, n=279$ ). Thus, faster distributional shifts generally occur in regions of faster isotherm shift. However, many distribution shifts seem not to be keeping pace with isotherm movement; biological responses lead or lag isotherms in ways that vary among and within taxonomic or functional groups (Fig. 3).

Differences between expected size of response and observed shifts may arise owing to mismatches between the spatial and temporal scales of the temperature data set and the local climate that the species is responding to, mismatches between the climate variable and biological measurement arising from poor understanding of mechanistic drivers, biases in data sets, and idiosyncratic species' responses ${ }^{16,17}$. For example in the Bering Sea, the extent of the cold pool $\left(<2^{\circ} \mathrm{C}\right.$ water $)$ located on the Bering Sea shelf separates Arctic and subarctic fauna. Ref. 18 presents evidence of a community-wide northward shift
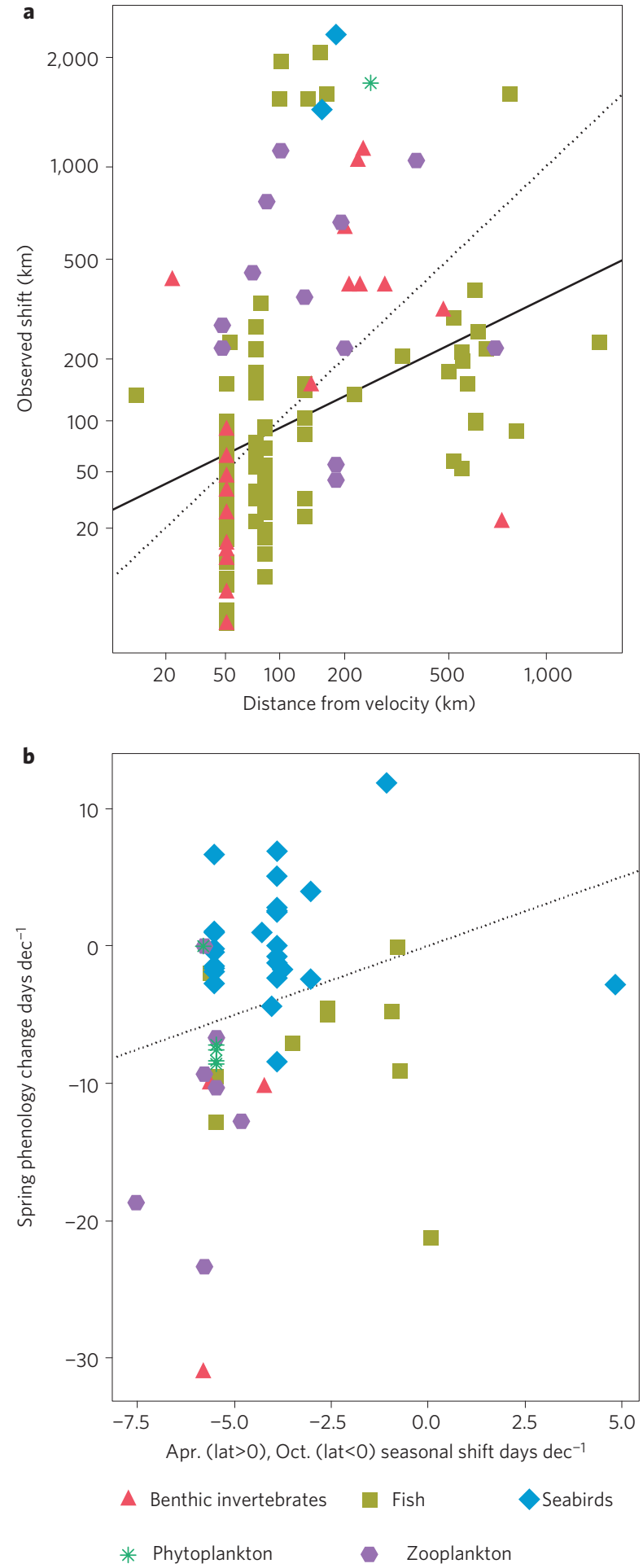

Figure 3 | a, Magnitude of observed shifts in species distributions $\left(\mathrm{km} \mathrm{dec}^{-1}\right)$ for marine taxonomic or functional groups against expected magnitude. Two hundred and seventy-nine observed shifts taken from 36 published studies (null responses excluded). b, Observed shifts in spring phenology (days $\mathrm{dec}^{-1}$ ) for marine taxonomic or functional groups against expected shift in spring phenology taken as shift in seasonal sea surface temperatures. Fifty-one observed shifts taken from 17 published studies. Expected distributional and phenology shifts over 1960-2009 calculated using the Hadley Centre data set (HadISST 1.1) and methods presented in ref. 8. April temperatures used for Northern Hemisphere spring phenology and October temperatures for Southern Hemisphere phenology. 
a

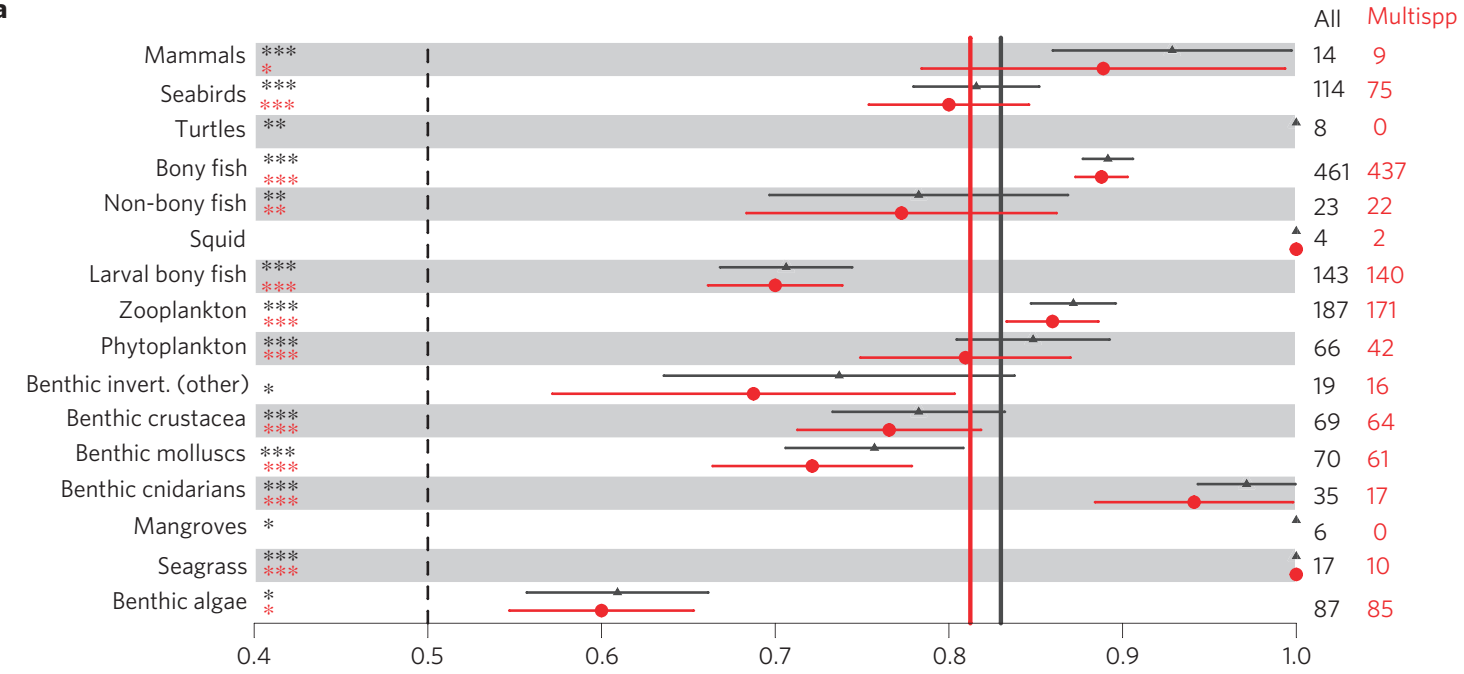

b

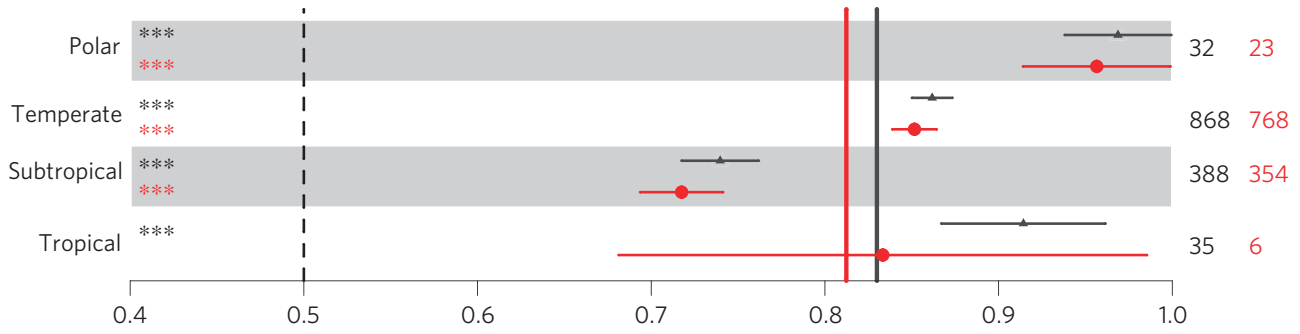

c

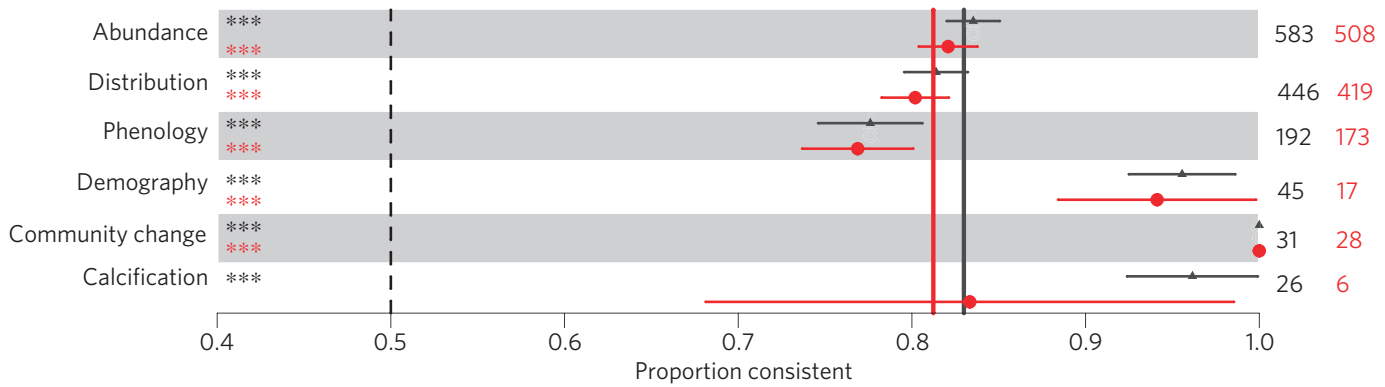

Figure 4 | Proportion of marine observations consistent with climate change predictions using observations from both single- and multi-species studies (all, black, $n=1,323$ ) and multi-species studies alone (red, $n=1,151)$. a-c, Mean and standard error of responses by taxonomic or functional group (a), latitudinal zone (b) and response type show significantly higher consistency than expected from random as determined by binomial tests for each estimate against 0.5 (dashed line at $50 \%$ consistency; c). The solid line is the mean across all observations. Significance of results is listed next to labels (***, $p<0.001 ; * *, p<0.01 ; *, p<0.05)$. Sample sizes are listed to the right of each row.

in demersal fauna related to loss of sea ice and northward retreat of this cold pool. However, variable responses among individual species in the community (some leading, some lagging temperature change and some not responding) are probably the result of interacting factors such as population size, dispersal ability, dependence on habitat or prey availability, resource competition, migratory strategy, latitudinal gradient in light regime, and fisheries impacts.

Observed shifts in seasonal timing of spring temperatures (1960-2009) are generally greater over the ocean than over land at high latitudes ${ }^{8}$ (above $45^{\circ}$ ). Given that the bulk of the quantitative phenological data are from higher latitudes, we expected that rates of response would be similar to or greater than those for terrestrial species. We found spring phenology in the ocean has advanced by $4.4 \pm 0.7$ days $\operatorname{dec}^{-1}\left(4.7 \pm 1.1{\text { days } \mathrm{dec}^{-1}}^{-1}\right.$ excluding single-species studies) and summer phenology by $4.4 \pm 1.1$ days $\mathrm{dec}^{-1}\left(4.0 \pm 0.6\right.$ days $\mathrm{dec}^{-1}$ excluding single-species studies; Fig. $2 \mathrm{~b}$ and Table 1$)$. Our results contrast with slower estimates, between 2.3 and 2.8 days $\mathrm{dec}^{-1}$ (Table 1), of spring phenological advancement on land ${ }^{12}$, also predominately from Northern Hemisphere temperate regions.

The strength of the phenological response to climate change for both marine and terrestrial species varies among taxonomic or functional groups ${ }^{12}$ (Fig. 2b). Phytoplankton, the main primary producers in the oceans, can respond rapidly to environmental changes compared with most terrestrial trees and plants, given their short generation times, sensitivity to temperature and advection of organisms within water masses ${ }^{19}$. The timing of phytoplankton blooms advanced much faster $\left(6.3 \pm 1.6\right.$ days $\mathrm{dec}^{-1}$ for multispecies assemblages) than that of plants on land (1.1-3.3 days $\mathrm{dec}^{-1}$; refs 12,20). Fastest rates of spring advancement were for pelagic

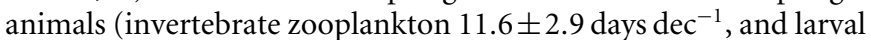
bony fish $11.2 \pm 1.7$ days dec $^{-1}$ and Fig. 2b). However, phyto- and zooplankton groups both show slower, and similar, advancement

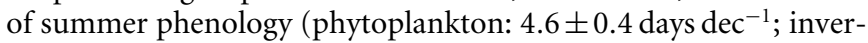
tebrate zooplankton: $4.6 \pm 1.0$ days $\mathrm{dec}^{-1}$ ). These variable responses across biological communities and seasonal cycles imply temporal mismatches between food requirements and availability ${ }^{21}$. 
Previous meta-analyses focusing on terrestrial species showed only weak relationships with shifts in seasonal temperature using latitude as a proxy ${ }^{3,12}$. We produced quantitative expectations for spring phenology shifts $(n=34$ phyto- and zooplankton plus $n=17$ seabirds; mostly from the North Atlantic), but found no relationship between these and corresponding seasonal temperature shifts (Fig. 3 and Supplementary Information). In marine ecosystems, nutrient availability, mixing (turbulence), solar irradiance, water-column stratification and grazing pressure combine to regulate the timing and magnitude of plankton blooms $s^{22,23}$, so the timing of seasonal temperatures may be too simple an indicator for these events.

Our final challenge was to evaluate global consistency in observed biological responses to climate change. Global coherence of biological responses such as changes in distribution, abundance, phenology and community structure, over the period during which climate change has been unequivocally linked to the rise of greenhouse gases, infers that anthropogenic climate change is, in part, a causal driver ${ }^{11,24}$. We extracted consistent and inconsistent observations (as identified by each study's authors) from our database across all response types $(n=1,323)$. These were used to test the hypothesis that marine responses were equally likely in either direction, as assessed by a binomial test against 0.5, the value expected if changes were random (Supplementary Methods). We excluded null responders, because apparent null responses can arise from a number of causes, such as poor data resolution, lags in species' responses, barriers to dispersal, or species' responses that are not driven by climatic factors ${ }^{11}$. Eighty-three per cent of observed changes were in the direction expected under climate change, and $81 \%(n=1,151)$ if data from only multi-species studies were selected (Fig. 4), well above the value expected by chance $(P<$ $0.0001)$. Proportions of observations consistent with climate change were significantly greater than $50 \%$ for all taxonomic or functional groups (Fig. 4a), biomes (Fig. 4b) and response types (Fig. 4c), but with substantial variability (see Supplementary Results). Our results corroborate those of a regional marine synthesis ${ }^{1}$ and also syntheses from predominately terrestrial species with global consistencies of 81-90\% (refs 3,4,11).

A major potential criticism of climate meta-studies is that supporting evidence may contain biases ${ }^{12}$. To investigate these, we compared analytical results from subsets of the database that were less prone to bias. We show above our results are robust to publication bias (Fig. 4). We selected subsets of observations that: span $30 \mathrm{yr}$ or more, reducing biases introduced through decadalscale variability (78\% consistency, $n=776$, Supplementary Fig. S5); and specifically discounted other drivers of change, reducing the influence of non-climate drivers (79\% consistency, $n=379$, Supplementary Fig. S6). These results show that our conclusions are robust when major known biases are accounted for.

Diagnostic fingerprints are uniquely predicted by twentiethcentury climate trends and provide convincing evidence that climate change is the primary driver behind the observed biological changes, strengthening attribution ${ }^{11,24}$. Such fingerprints include: opposing responses in warm-water and cool-water species within a community, or at leading and trailing range ranges; and similar responses from discrete populations at the same range edge (for example northwest Atlantic and northeast Atlantic populations). We find numerous examples of these in our database (see Supplementary Information). For example, for 33 species, observations were available from both leading and trailing range edges, or from distant, leading-edge populations. Twenty-four of these showed responses at all sites that were consistent with climate change, namely expansion or increased abundance at leading edges, and/or contraction or decreased abundance at trailing range edges.

In conclusion, recent climate studies show that patterns of warming of the upper layers of the world's oceans are significantly related to greenhouse gas forcing ${ }^{25,26}$. Global responses of marine species revealed here demonstrate a strong fingerprint of this anthropogenic climate change on marine life. Differences in rates of change with climate change amongst species and populations suggest species' interactions and marine ecosystem functions may be substantially reorganized at the regional scale, potentially triggering a range of cascading effects ${ }^{27}$. Significantly, $24 \%$ of the species in our database showed no response, which may arise from diverse circumstances including limited observational resolution, poor process understanding, antagonistic and synergistic interactions among multiple drivers of change, and evolutionary adaptation. A focus on understanding the mechanisms underpinning the nature and magnitude of responses of marine organisms to climate change can help forecast impacts and the associated costs to society and facilitate adaptive management strategies effective in mitigating these impacts. This study not only provides compelling evidence for widespread impacts of climate change in the ocean, but also predicts future reconfiguration of marine ecosystems, and the services they provide.

\section{Methods}

We reviewed the published literature to compile a global database of observations of marine biological responses to regional and global climate change, including null responses and studies where expectations of climate change responses were considered and rejected (Fig. 1). We searched ISI Web of Science using key words including climate change, warming, acidification, calcification and phenology. We define an observation as a single biological response (classified into phenology, distribution, abundance, community composition, demography or calcification) that was tested, or at a minimum discussed, in relation to expected impacts of recent climate change. These included cases where biological responses were consistent with regional climate change, and where regional climate change did not explain biological responses (inconsistent) or there was a lack of biological response (null responders). Ninety-six per cent of the observations in our database identified temperature as the primary climate change driver, with the remainder relating biological change to $\mathrm{pH}$, sea ice extent, sea level rise or climate oscillations.

To be included in our database, a study had to meet three criteria: authors inferred or directly tested for trends in biological and climatic variables; data after 1990 were included; and to minimize the chance of bias resulting from short-term biological responses to natural climate variability, observations spanned at least 19 years. We included data from continuous data series (number of observations, $n=1,096,>48,000$ data points), intermittent data series $(n=271)$ and comparisons of two periods in time $(n=368)$, if they met our criteria. From each study we extracted data on the characteristics of observations including location and duration of study, the number of data points collected, and the direction of observed change in the biological parameter (if any; Supplementary Table S1). Where species were encountered more than once, we retained only the observation from the longest time series or most robust analysis, unless the observations were from separate regions or of different types (for example, distribution and phenology). We did not restrict our search to only studies that applied a statistical test of a relationship between observed climate change and observed biological response. Most studies supplied multiple lines of evidence from theory, process-understanding, historical overview and experimental and field results, to contextualize findings of a response to climate change.

We categorized each observation as no change $(n=418)$ in response to climate change, consistent $(n=1,092)$, or inconsistent $(n=225)$ with climate change on the basis of the original authors' interpretations (Supplementary Methods). Examples of expectations consistent with climate change are poleward distribution shifts, earlier timing with warming and declining calcification rates. However, we also captured responses that were contrary to general expectations under climate change, such as equatorward range contractions, but consistent with regional climate change such as areas of cooling. Quantitative estimates of shifts in distributions and phenology were taken directly from the papers, calculated from information in figures and tables, or, in some cases, supplied on request by the authors of the study.

We extracted subsets of data to address three questions. We used data reported as kilometres per decade or days per decade or to examine mean rates of shifts in distribution $(n=362)$ and spring $(n=52)$ and summer phenology $(n=51)$. We included negative and null responses in these analyses as we were focused on global response to climate change across all species and taxonomic groups ${ }^{12}$. We then used this subset to determine whether responses in distribution and spring phenology were tracking changes in regional temperatures. We excluded null responses ( $23 \%$ distribution and $<2 \%$ phenology observations) to avoid over-inflation of zero data. For distribution change, we took the absolute distance 
shifted, irrespective of direction. For each quantitative shift in our database for distribution and phenology, excluding null observations, expectations regarding the velocity of temperature isotherms (VoCC) and the shift in seasonal temperatures (SCS) were produced using the data sets and methods described in ref. 8 over the period 1960-2009. Distribution shifts were matched to VoCC values by averaging all values from $1^{\circ}$ grid cells within a circular buffer distance (size of reported shift) from each observation. Spring phenology responses were similarly matched to SCS values for April (Northern Hemisphere) and October (Southern Hemisphere). The buffer radius was set as the square root of the reported area of each observation, divided by $\pi$.

Finally, to show a global coherence of biological responses to climate change, we applied the vote-counting approach ${ }^{4,5,11}$ using consistent and inconsistent observations to test for a coherent pattern in responses across regions, taxonomic or functional groups, using all available data $(n=1,323)$ and only multi-species studies $(n=1,151)$

\section{Received 13 August 2012; accepted 24 June 2013; published online XX Month XXXX}

\section{References}

1. Tasker, M. L. The Effect of Climate Change on the Distribution And Abundance of Marine Species in the OSPAR Maritime Area ICES Coop. Res. Rep. No. 293, 45 (2008).

2. Chen, I. C., Hill, J. K., Ohlemuller, R., Roy, D. B. \& Thomas, C. D. Rapid range shifts of species associated with high levels of climate warming. Science 333, 1024-1026 (2011).

3. Root, T. L. et al. Fingerprints of global warming on wild animals and plants. Nature 421, 57-60 (2003).

4. Rosenzweig, C. et al. Attributing physical and biological impacts to anthropogenic climate change. Nature 453, 353-358 (2008).

5. Przeslawski, R., Falkner, I., Ashcroft, M. B. \& Hutchings, P. Using rigorous selection criteria to investigate marine range shifts. Estuar. Coast. Shelf Sci. 113, 205-212 (2012).

6. Sorte, C. J. B., Williams, S. L. \& Carlton, J. T. Marine range shifts and species introductions: Comparative spread rates and community impacts. Glob. Ecol. Biogeogr. 19, 303-316 (2010).

7. IPCC Climate Change 2007: The Physical Science Basis 976 (Cambridge Univ. Press, 2007).

8. Burrows, M. T. et al. The pace of shifting climate in marine and terrestrial ecosystems. Science 334, 652-655 (2011).

9. Hoegh-Guldberg, O. \& Bruno, J. F. The impact of climate change on the World's marine ecosystems. Science 328, 1523-1528 (2010).

10. Doney, S. C. et al. Climate change impacts on marine ecosystems. Ann. Rev. Mar. Sci. 4, 11-37 (2012).

11. Parmesan, C. \& Yohe, G. A globally coherent fingerprint of climate change impacts across natural systems. Nature 421, 37-42 (2003).

12. Parmesan, C. Influences of species, latitudes and methodologies on estimates of phenological response to global warming. Glob. Change Biol. 13, 1860-1872 (2007).

13. Sunday, J. M., Bates, A. E. \& Dulvy, N. K. Thermal tolerance and the global redistribution of animals. Nature Clim. Change 2, 686-690 (2012).

14. Loarie, S. R. et al. The velocity of climate change. Nature 462, 1052-1055 (2009).

15. Van der Wal, J. et al. Focus on poleward shifts in species' distributions underestimates the fingerprint of climate change. Nature Clim. Change http://dx.doi.org/doi:10.1038/NCLIMATE1688 (2012).
16. Parmesan, C. et al. Beyond climate change attribution in conservation and ecological research. Ecol. Lett. (in the press, 2013).

17. Devictor, V. et al. Differences in the climate debts of birds and butterflies at a continental scale. Nature Clim. Change http://dx.doi.org/doi:10.1038/NCLIMATE1347 (2012).

18. Mueter, F. J. \& Litzow, M. A. Sea ice retreat alters the biogeography of the Bering Sea continental shelf. Ecol. Appl. 18, 309-320 (2008).

19. Beaugrand, G. Decadal changes in climate and ecosystems in the North Atlantic Ocean and adjacent seas. Deep-Sea Res. II 56, 656-673 (2009).

20. Wolkovich, E. M. et al. Warming experiments underpredict plant phenological responses to climate change. Nature 485, 494-497 (2012).

21. Edwards, M. \& Richardson, A. J. Impact of climate change on marine pelagic phenology and trophic mismatch. Nature 430, 881-884 (2004).

22. Pau, S. et al. Predicting phenology by integrating ecology, evolution and climate science. Glob. Change Biol. http://dx.doi.org/10.1111/j.1365-2486.2011.02515.x (2011).

23. Sapiano, M. R. P., Brown, C. W., Schollaert, Uz, S. \& Vargas, M. Establishing a global climatology of marine phytoplankton phenological characteristics. J. Geophys. Res. 117, C08026 (2012).

24. Parmesan, C., Duarte, C., Poloczanska, E., Richardson, A. J. \& Singer, M. C. Overstretching attribution. Nature Clim. Change 1, 2-4 (2011).

25. Levitus, S. et al. Global ocean heat content 1955-2008 in light of recently revealed instrumentation problems. Geophys. Res. Lett. 36 http://dx.doi.org/doi:10.1029/2008gl037155 (2009).

26. Barnett, T. P. et al. Penetration of human-induced warming into the world's oceans. Science 309, 284-287 (2005).

27. Ling, S. D. \& Johnson, C. R. Population dynamics of an ecologically important range-extender: Kelp beds versus sea urchin barrens. Mar. Ecol. Prog. Ser. 374, 113-125 (2009).

\section{Acknowledgements}

This work was conducted as a part of the Understanding Marine Biological Impacts of Climate Change Working Group supported by the National Center for Ecological Analysis and Synthesis, a centre funded by NSF (Grant \#EF-0553768), the University of California, Santa Barbara, and the State of California.

\section{Author contributions}

E.S.P. and A.J.R. led the NCEAS working group. E.S.P., A.J.R., C.J.B., P.J.M., S.A.T. and W.J.S. extracted data from publications for the database. E.S.P., A.J.R. and C.B. undertook quality-control of the database. E.S.P., C.P. and W.J.S. wrote the first draft of the paper. W.K., C.J.B., A.J.R., M.T.B., E.S.P. and D.S.S. ran analyses and produced figures and tables. All authors contributed equally to discussion of ideas, development of the database and analyses, and commented on the manuscript

\section{Additional information}

The Marine Impacts Database (NCEAS 12449: Richardson and Poloczanska E. 2013: Towards understanding marine biological impacts of climate change, National Center for Ecological Analysis and Synthesis. Impacts of Climate Change on Marine Organisms) is available at http://knb.ecoinformatics.org $/ \mathrm{knb} /$ metacat $/$ nceas.1000.1/nceas.

Supplementary information is available in the online version of the paper. Reprints and permissions information is available online at www.nature.com/reprints. Correspondence and requests for materials should be addressed to E.S.P.

\section{Competing financial interests}

The authors declare no competing financial interests. 
Page 1

Query 1:

Please provide postcode for affiliation 7.

\section{Page 6}

Query 2:

Please check that the intended meaning of the sentence 'We extracted subsets ... $(n=51)$.' has been retained after editing.

Page 7

Query 3:

Can the text be amended to avoid the use of the acronyms 'VoCC' and 'SCS'? (According to style, acronyms should be used at least three times in the text; otherwise the terms should be written in full throughout, where possible.)

\section{Query 4:}

Please provide publisher's name for ref. 1, also does the page number provided for this reference represent the total number of pages in the book or the first page of the relevant page range? If the latter, please provide the final page number of that range.

Query 5:

Does the page number provided in reference 7 represent the total number of pages in the book or the first page of the relevant page range? If the latter, please provide the final page number of that range.

Query 6:

Please provide page range and volume for refs 15 , 17, 22 and 25.

Query 7:

Any update for ref. 16 ?
Query 10:

Please check that the layout of table 1 is $\mathrm{OK}$.

Query 11:

Please provide short title for Figures 1,2 and 3.

\section{General Queries}

Query 8:

Please note that reference numbers are formatted according to style in the text, so that any reference numbers following a symbol or acronym are given as 'ref. XX' on the line, whereas all other reference numbers are given as superscripts.

\section{Query 9:}

Text amended throughout to avoid the use of numbered lists, and the use of author names, according to style; please check. 